\title{
The Role of Coconut Water on Nicotine-Induced Reproductive Dysfunction in Experimental Male Rat Model
}

\author{
Sandhya Vijayam Gopalakrishnan Nair, Thankappan Rajamohan* \\ Department of Biochemistry, University of Kerala, Trivandrum, India \\ Email: ${ }^{*}$ rajamohant@yahoo.com
}

Received 3 February 2014; revised 21 March 2014; accepted 2 April 2014

Copyright (C) 2014 by authors and Scientific Research Publishing Inc.

This work is licensed under the Creative Commons Attribution International License (CC BY). http://creativecommons.org/licenses/by/4.0/

(c) (i) Open Access

\begin{abstract}
The coconut water is the most nutritious wholesome beverage in all coconut producing countries. Folk medicine describes the use of coconut water to reduce toxic effects of nicotine and alcohol in reproductive function in men, but its direct evidence is lacking. The aim of this study was to investigate the effects of tender and mature coconut water consumption on nicotine induced changes in sperm quality, spermatogenic cell density, activity of testicular marker enzymes for spermatogenesis and testosterone level of male healthy rats. Male Sprague Dawley rats were treated with tender and mature coconut water intragastrically and nicotine subcutaneously for 15 days. The findings indicated that the coconut water supplementation improves epididymal spermatogenic cell density $(p \leq 0.05)$, sperm motility and morphology which were altered by nicotine. The activity of acid phosphatase and alkaline phosphatase was increased $(p \leq 0.05)$, which indicates that treatment with coconut water provides significant protection of germinal epithelium from nicotine toxicity. Coconut water also shows a significant increase $(p \leq 0.05)$ in testosterone levels in nicotine treated rats. Coconut water ameliorates the reproductive toxicity caused by nicotine due to presence on nutrients L-arginine, ascorbic acid, minerals like calcium and magnesium.
\end{abstract}

\section{Keywords}

Rat Sperm, Testosterone, Nicotine, Coconut Water, L-Arginine

\section{Introduction}

Nicotine, most important alkaloid constituent of tobacco, causes injurious effect on reproductive system as well

*Corresponding author.

How to cite this paper: Nair, S.V.G. and Rajamohan, T. (2014) The Role of Coconut Water on Nicotine-Induced Reproductive Dysfunction in Experimental Male Rat Model. Food and Nutrition Sciences, 5, 1121-1130.

http://dx.doi.org/10.4236/fns.2014.512122 
as fertility of male smokers and consumers of smokeless tobacco [1]. Nicotine and its oxidized metabolite cotinine adversely affected spermatogenesis, epididymal sperm count, motility, and the fertilizing potential of sperms [2]. Nicotine inhibits testosterone biosynthesis along with reduction in testicular androgenic enzymes in mature rats [3] [4]. Nicotine and cotinine can across the blood-testis barrier and have been found at significant levels in seminal plasma in humans that significantly decrease semen quality demonstrated by reduced sperm viability and altered morphology [5] [6]. The increased testicular lipid peroxidation, hydrogen peroxide and hydroxyl radical generations, as well as decreased glutathione level, reduced antioxidant enzymes activities and mitochondrial membrane potential $(\Delta \psi \mathrm{m})$ of testis were reported nicotine treated rats [1]. Several studies have reported that nutritional therapies can improve negative impact on spermatogenesis caused by life style risk factors like smoking or use of alcohol [7]. Nutritional therapies including carnitine, arginine, zinc, selenium, vitamin B-12 and antioxidants such as vitamin C, vitamin E, glutathione, and coenzyme Q10 have been shown to improve sperm counts, sperm motility and male infertility [7].

The coconut water is the most nutritious wholesome beverage in all coconut producing countries. Coconut water, the liquid endosperm of coconut, contains sugars, vitamins, minerals, proteins, free amino acids and growth promoting factors. It is mainly consumed as tender and mature forms. Our previous reported studies showed that both tender and mature coconut water feeding significantly reduced hyperlipidemia in cholesterol fed rats [8] [9]. Tender coconut water has significant cardioprotective and antithrombotic effect in rats induced myocardial infraction [10] Tender coconut water showed potent hepatoprotective and antioxidant effects in carbon tetrachloride $\left(\mathrm{CCl}_{4}\right)$-intoxicated rats [11]. Tender coconut water could prevent and reverse high blood pressure, upregulate antioxidant status and improved insulin sensitivity [12]. In this study, therefore, the changes in sperm function, testicular enzymatic and hormonal milieu after nicotine treatment with or without tender and mature water were investigated.

\section{Materials \& Methods}

\subsection{Collection of Coconut Water}

Fresh coconuts of tender stage (six months maturity) and mature stage (10 months maturity) were harvested from the coconut tree (Cocos nucifera) (west coast tall variety) grown on the University campus, dehusked, broken carefully and liquid endosperm were collected and used for each day experiment.

\subsection{Animals}

Male Sprague Dawley rats weighing 140 - 150 g were housed individually in polypropylene cages in room maintained at $25^{\circ} \mathrm{C} \pm 1{ }^{\circ} \mathrm{C}$ with alternate exposure to light and dark for 12 hours. The animals were maintained according to the "Guide for the Care and Use of Laboratory Animals" [13] and the protocol were approved by our institutional ethics committee.

\subsection{Treatments}

Rats were divided into four groups of 6 rats in each and treated as follows:

Group 1 Normal rat (Control);

Group 2 Nicotine administered;

Group 3 Nicotine $+4 \mathrm{ml}$ tender coconut water;

Group 4 Nicotine $+4 \mathrm{ml}$ mature coconut water.

Nicotine (Sigma chemicals) dissolved in physiological saline and $\mathrm{pH}$ adjusted to 7.2 with sterile $0.1 \mathrm{~N} \mathrm{HCl}$ was administered subcutaneously at a dose of $0.1 \mathrm{mg} / 100 \mathrm{~g}$ body weight daily and the controls received a similar amount of saline. Rats of group 3 were given TCW and group 4 were given MCW at a single, daily dose level of $4 \mathrm{ml} / 100 \mathrm{~g}$ body weight intragastric daily. The caloric intake in rats fed coconut water and those without coconut water are kept the same by providing glucose (120 $\mathrm{mg}$ in $4 \mathrm{ml}$ ) along with the drinking water. The animals were fed the diet and drinking water ad libitum for 15 days.

\subsection{Methods}

At the end of study period, the rats were deprived of food overnight, and sacrificed by decapitation without anesthesia. Trunk blood were collected and the testes, epididymis, seminal vesicle and ventral prostate were 
dissected, cleared of the fat and connective tissue were weighed and removed to ice cold containers for various estimations.

\subsubsection{Epididymal Sperm Count}

Epididymal sperm count of the control and treated animals was determined by the method as described in the WHO manual [14]. An incision was made through the cauda of right epididymis, light pressure was applied to this region, and sperm was extruded. To $1 \mathrm{ml}$ of Ham's F-10 medium, $10 \mu \mathrm{l}$ sperm of control and experimental group were suspended. After centrifugation, $5 \mu \mathrm{L}$ epididymal sperm was diluted with $95 \mu \mathrm{L}$ of diluent $(2.5 \mathrm{~g}$ sodium bicarbonate, $500 \mu \mathrm{L}$ of $35 \%$ formalin, and $12.5 \mathrm{mg}$ of trypan blue in $50 \mathrm{~mL}$ of distilled water) and counted using Neubauer hemocytometer. Live sperms appeared bright and colorless whereas dead sperms showed blue heads.

\subsubsection{Sperm Morphology}

To assess the percentage of morphologically abnormal sperm, the cauda of right epidydmis was rinsed with $0.5 \mathrm{~mL}$ of physiological saline $(0.9 \% \mathrm{NaCl})$ to obtain a sperm suspension. Aliquots of sperm suspension were stained with $2 \%$ eosin. Hundred spermatozoa per animal were analyzed microscopically at $400 \times$ magnification and counted spermatozoa with abnormal traits as follows twisted body, detached head, round tails and abnormal neck.

\subsubsection{Testicular Acid Phosphatase (ACP) and Alkaline Phosphatase (ALP) Activities}

The activity of ACP was estimated using the testicular tissue homogenate $(250 \mu \mathrm{l})$ in $0.09 \mathrm{M}$ citrate buffer solution ( $\mathrm{pH} 4.8$ ) which was then added to the substrate, 4-nitrophenyl phosphate in citrate buffer solution [15]. After incubating at $37^{\circ} \mathrm{C}$ for 30 minutes, stop solution $(0.5 \mathrm{~N} \mathrm{NaOH})$ was added and read the absorption at $405 \mathrm{~nm}$. For determination of alkaline phosphatase [16], the tissue homogenate in $1 \mathrm{M}$ Tris $\mathrm{Hcl}(\mathrm{pH} 7.5)$ and $250 \mu \mathrm{l}$ of homogenate media was added to $1 \mathrm{ml}$ buffer containing $1 \mathrm{mM}$ PNPP in $1 \mathrm{M}$ Tris buffer, $\mathrm{pH}$ 7.5. The mixture was incubated at $37^{\circ} \mathrm{C}$ for $30 \mathrm{~min}$ in a water bath and the activity was measured spectrophotometrically at 405 $\mathrm{nm}$. The concentration of the sample was obtained from a standard curve and expressed as microgram of PNP liberated/mg of tissue/h.

\subsubsection{Serum Testosterone Concentration}

Serum testosterone was measured using commercially available ELISA kit (Kamiya biomedical company, USA) according to supplier's protocol. The cross-reaction of the testosterone antibody to dehydrotestosterone was $10 \%$ and intra-run precision had a coefficient of variation of $6.2 \%$.

\subsubsection{Serum Cholesterol and Extracted Testis Cholesterol}

Serum Cholesterol was estimated using enzy-colorimetric test kit purchased from Agappe Diagnostics. The total cholesterol in testis tissue were extracted and estimated by the method of Carr and Drekter [17].

\subsubsection{Statistical Analysis}

The Statistical analysis was done by one-way ANOVA utilizing the F test. The results are presented as the mean value \pm SD for the control and treated groups. Differences among the means for the groups were assayed using the Duncan's Multiple Range Test to determine which mean values were significantly different at $p \leq 0.05$.

\section{Results}

\subsection{Growth, Food Consumption, Weight Change of Sex Organs and Epididymal Sperm Count}

None of the animals treated with nicotine showed any signs of illness during the experimental period. Nicotine treated control or experimental group showed no differences in food consumption throughout the experimental schedule (data not shown). Administration of nicotine has caused significant reduction in the weight of testis and accessory sex organs with respect to its saline treated controls. On coconut water supplementation, weights of testis and accessory sex organs recovered remarkably $(\mathrm{p} \leq 0.05)$, from the nicotine toxicity (Figure 1$)$. The significant $(\mathrm{p} \leq 0.05)$ decrease of the epididymal sperm count, percentage motility and defective oscillatory 

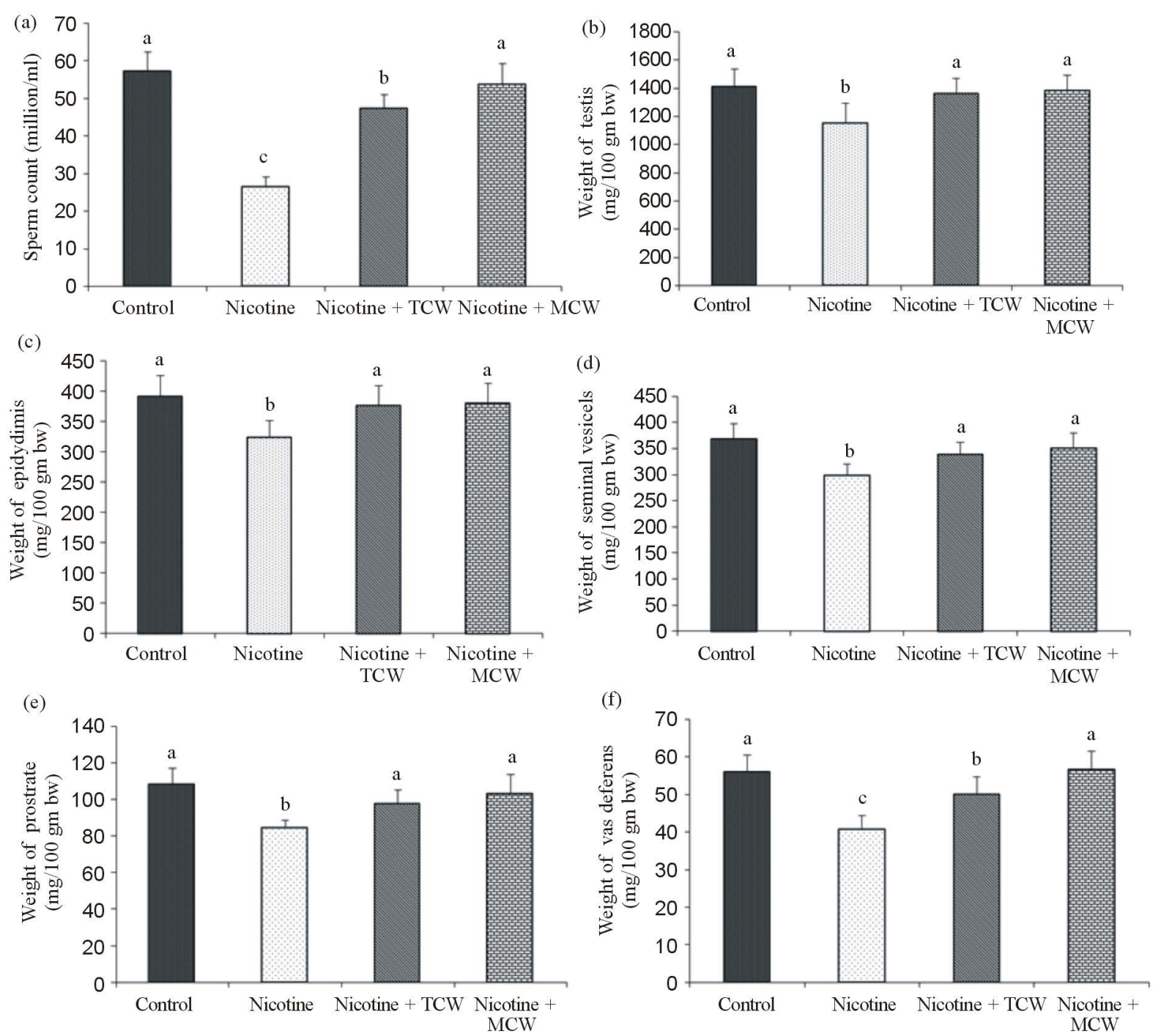

Figure 1. Effect of cosupplementation of tender and mature coconut water on epididymal sperm count (a) and weight of testis (b) and accesory sex organs epididymis (c), seminal vesicels (d), prostrate (e) and vas deferens (f) in nicotine treated rats. Data are expressed as mean \pm SD $(n=6)$. Columns not sharing the same superscript letter differ significantly $(p \leq 0.05)$.

movement in all the nicotine-treated rats in comparison with the control rats supported the detrimental effects of nicotine on the spermatozoa. Coconut water coadministration with nicotine showed significantly $(\mathrm{p} \leq 0.05)$ higher epididymal sperm density in comparison with the nicotine treated control rats. Mature coconut water showed significant $(\mathrm{p} \leq 0.05)$ improvement in vas deferens weight and sperm count compared to group cosupplemented with tender coconut water.

\subsection{Sperm Morphology and Motility}

Increased abnormalities of sperm head in nicotine treated rats compared to control ensured the detrimental effect of nicotine on spermatozoa. Abnormal spermatozoa with twisted body, detached head, abnormal neck, round tail were predominant following nicotine exposure. The percentage of sperm with progressive movement was significantly $(\mathrm{p} \leq 0.05)$ reduced on nicotine treatment. Coconut water supplementation significantly protected the sperms from the damaging effect of nicotine and exhibited a significant $(\mathrm{p} \leq 0.05)$ decrease in percentage abnormality and improved progressive movement compared to nicotine treated rats (Figure 2). Mature coconut water showed significant ( $\mathrm{p} \leq 0.05)$ sperm protective effect by decreased abnormality and increased rate of progressive movement compared to rats cosupplemented with tender coconut water. 
(a)

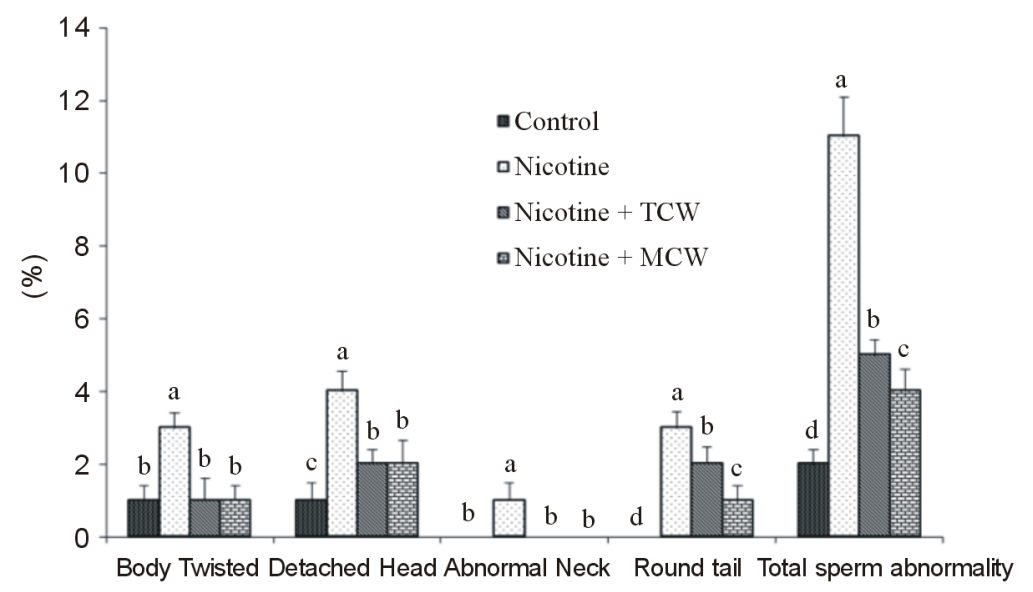

(b)

Progressive movement
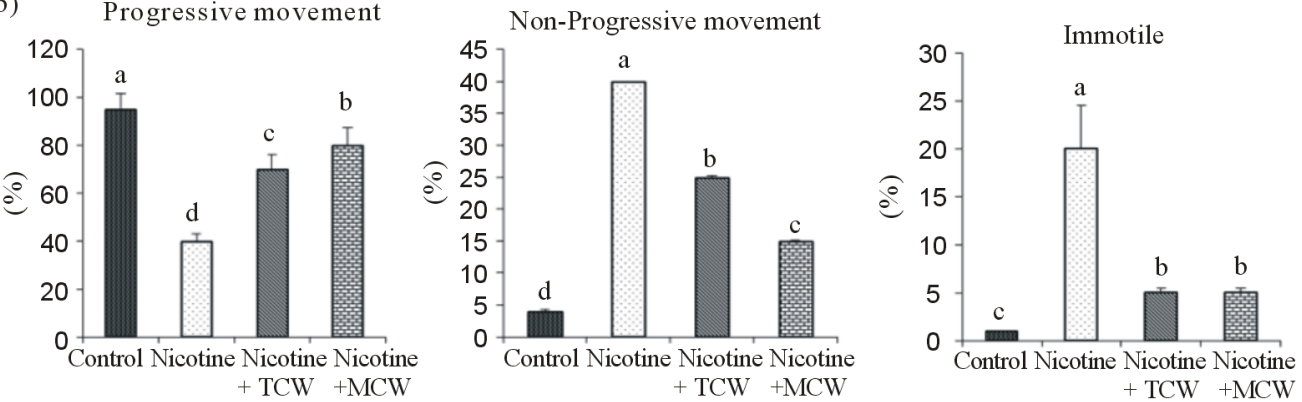

(c)

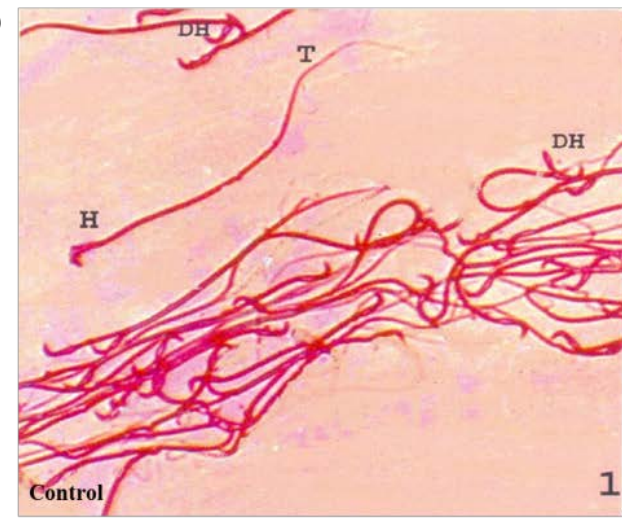
$+\mathrm{TCW}+\mathrm{MCW}$

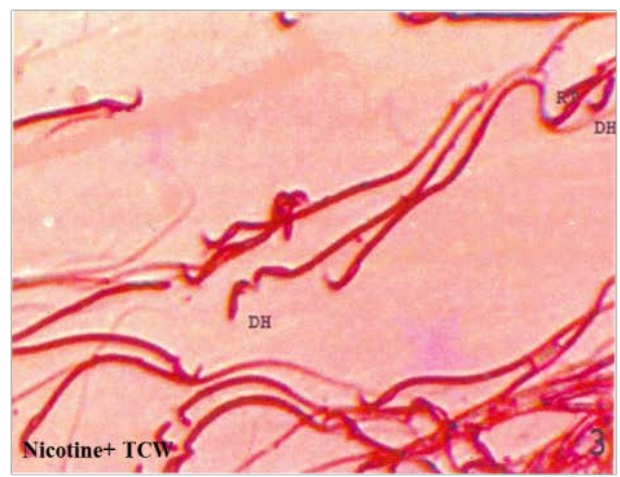

1 Nicotine
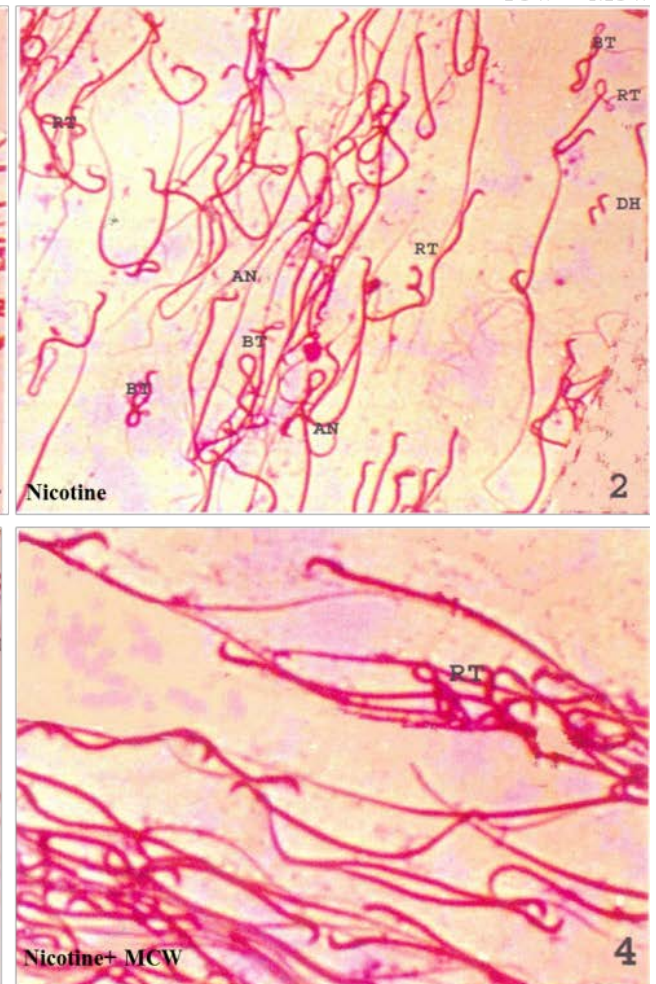

Figure 2. Effect of cosupplementation of tender and mature coconut water on sperm abnormality (a), mode of movement at zero minutes (b) and sperm morphology (c) in nicotine treated rats. Data are expressed as mean \pm SD $(n=6)$. Columns not sharing the same superscript letter differ significantly $(\mathrm{p} \leq$ 0.05). Images are the representative of three independent experiments. Body Twisted (BT), Detached Head (DH), Abnormal Neck (AN), Round tail (RT). 


\subsection{Testicular Activity of Acid Phosphatase \& Alkaline Phosphatase}

The testicular ACP and ALP activities showed a significant $(\mathrm{p} \leq 0.05)$ increase in all the nicotine-treated animals compared to the control revealing the degenerative changes in testicular parenchyma, followed by nicotine exposure Coconut water cosupplementation with nicotine significantly $(\mathrm{p} \leq 0.05)$ decreased these testicular enzymes activities toward normal control rats (Figure 3). Acid Phosphatase activity was significantly ( $\leq \leq 0.05$ ) lowered in tender coconut water treated group compared to rats cosupplemented with mature coconut water.

\subsection{Concentrations of Testosterone in Serum}

Nicotine significantly decreased $(\mathrm{p} \leq 0.05)$ the serum testosterone compared to control demonstrating the inhibitory effect of nicotine on testicular androgenesis. However, coconut water coadministration with nicotine significantly augmented serum testosterone concentration with respect to the nicotine alone treated animals suggesting that coconut water has a stronger influence on testicular androgenesis (Figure 4). The effect of mature coconut water was strongest in improving the testosterone concentration compared to tender coconut water cosupplemented group.
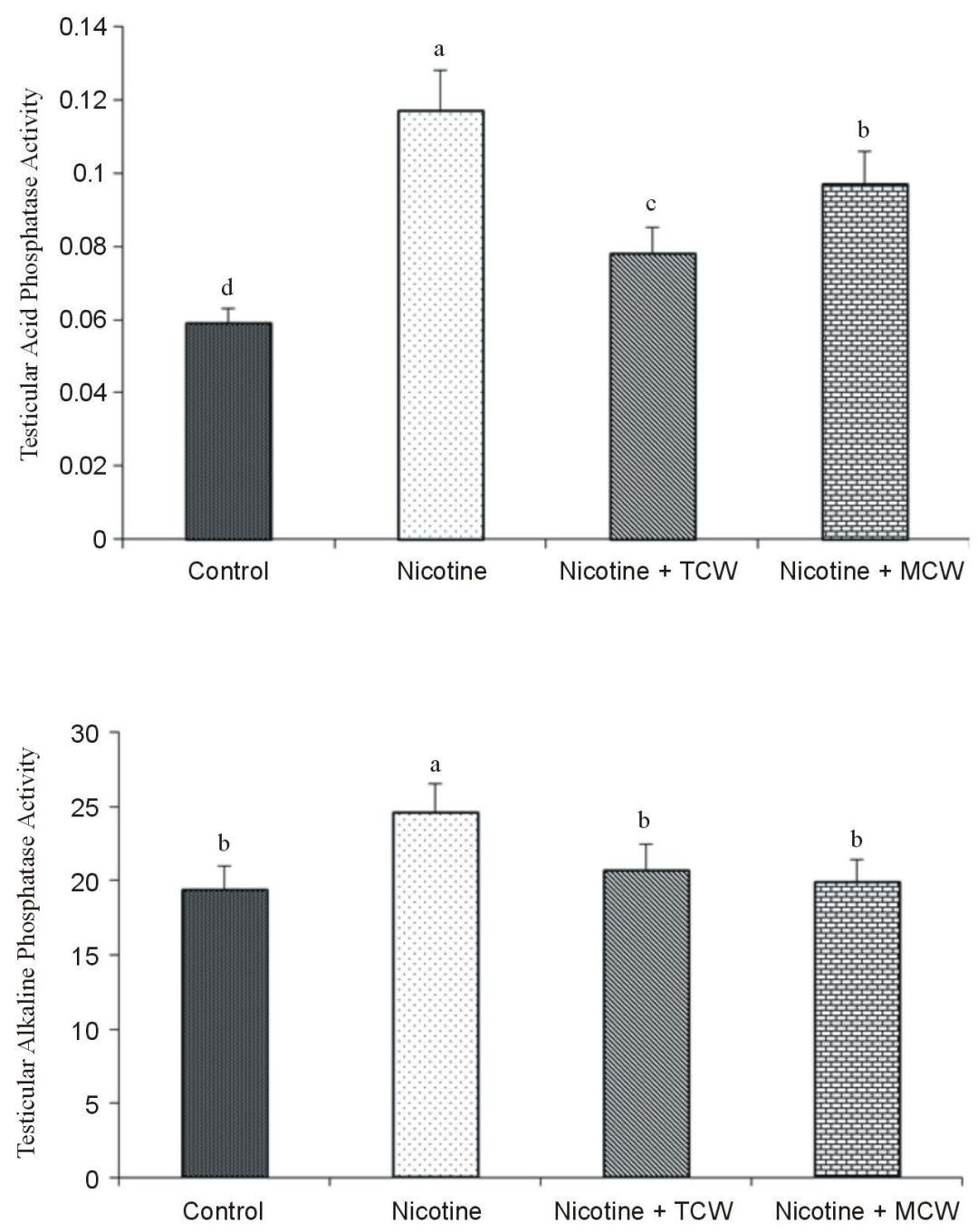

Figure 3. Effect of cosupplementation of tender and mature coconut water on testicular activity of acid phosphatase \& alkaline phosphatase (measured as micromoles of p-nitrophenol liberated) in nicotine treated rats. Data are expressed as mean \pm SD $(\mathrm{n}=6)$. Columns not sharing the same superscript letter differ significantly $(\mathrm{p} \leq$ $0.05)$. 


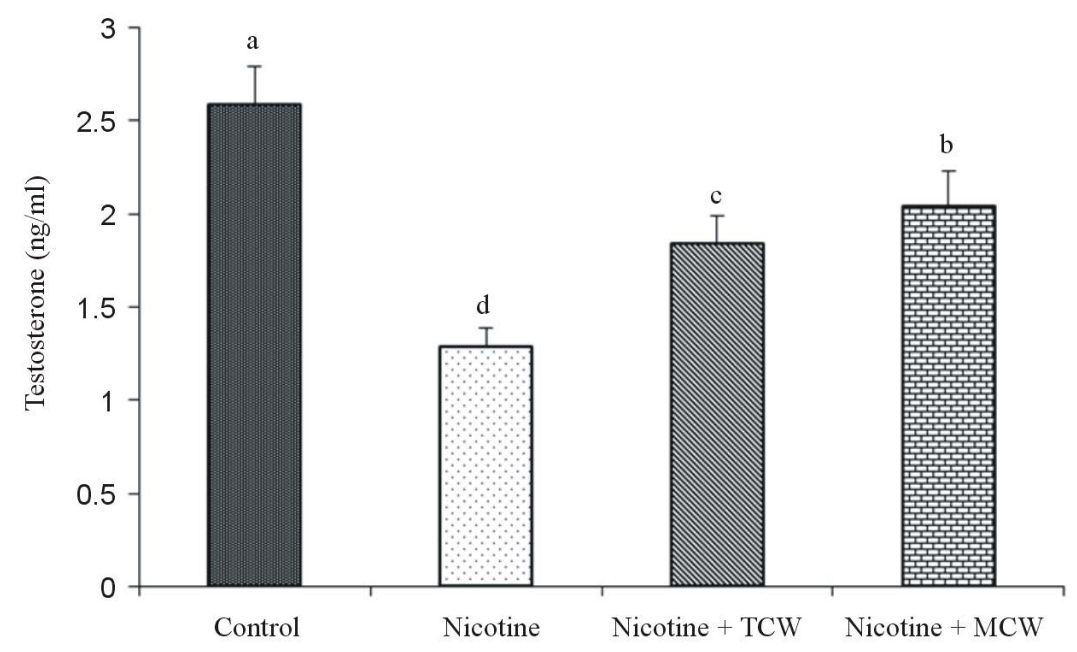

Figure 4. Effect of cosupplementation of tender and mature coconut water on concentration of serum testosterone in nicotine treated rats. Data are expressed as mean \pm SD $(n=6)$. Columns not sharing the same superscript letter differ significantly $(\mathrm{p} \leq 0.05)$.

\subsection{Concentration of Cholesterol in Serum and Testes}

Rats administered nicotine showed a significant $(\mathrm{p} \leq 0.05)$ increase in cholesterol in the serum, and testis as compared to the control rats. Supplementation of coconut water lowered the cholesterol in nicotine treated rats (Figure 5). Mature coconut water was better in lowering $(\mathrm{p} \leq 0.05)$ testis cholesterol than tender coconut water received group.

\section{Discussion}

The results of this study revealed that tender and mature coconut water administration significantly improves sperm count, motility, morphology and plasma testosterone in nicotine intoxicated rats. Coconut water contains several biologically active components including free amino acid L-arginine, ascorbic acid, minerals such as calcium, magnesium and potassium. Several studies have proven the beneficial effect of these components on sperm counts and sperm motility. Arginine supplementation significantly improved sperm motility without any side effects in men [18]. Ascorbic acid treatment increased sperm count and caused significant reductions in the number of agglutinated sperm in infertile men [19]. Our previous studies had proven the lipid lowering effect of coconut water in serum and tissue in rats [8] [9]. The changes observed in nicotine treatment, in this study, agree with the previous reports which demonstrated that nicotine causes reduction in epidydimal sperm count, motility and impairs testicular function [1]. Coconut water improved the reduced testicular weights, a valuable index of reproductive toxicity in male [20]. Among the biologically active compounds in coconut water, L-arginine plays a major role. Analysis of chemical constituents indicates that TCW contains $30 \mathrm{mg} \%$ of L-arginine while MCW contains $150 \mathrm{mg} \%$. L-arginine is a nutritionally essential amino acid for spermatogenesis. Dietary L-arginine supplementation to men increased sperm counts and sperm motility [16] [21]. Seminal fluid is particularly abundant in polyamines (putrescine, spermidine and spermine), polycationic products of L-arginine degradation, that are essential for cell growth and differentiation [22]. Enhancing L-arginine provision may improve fertility in males by enhanced synthesis of polyamines and L-arginine rich basic proteins in sperm cells; and regulating nitric oxide required in sperm motility [23]. Nicotine and its metabolite cotinine have a direct cytotoxic effect on spermatozoa by damaging DNA [24]. L-arginine also protects testicular tissue and preserves the spermatozoa against lipid peroxidation [25].

Previous studies showed that tender coconut water showed the free radical scavenging ability that may be partly attributed to the ascorbic acid, which is an important constituent of coconut water [11] [24]. On maturity, the scavenging ability shown to be decreased [26] but the level of L-arginine is higher in mature coconut water which might contribute the protection effect on sperm count and viability on nicotine treatment. Supplementation of vitamin C in infertile men improved sperm count, sperm motility, sperm morphology and the semen 

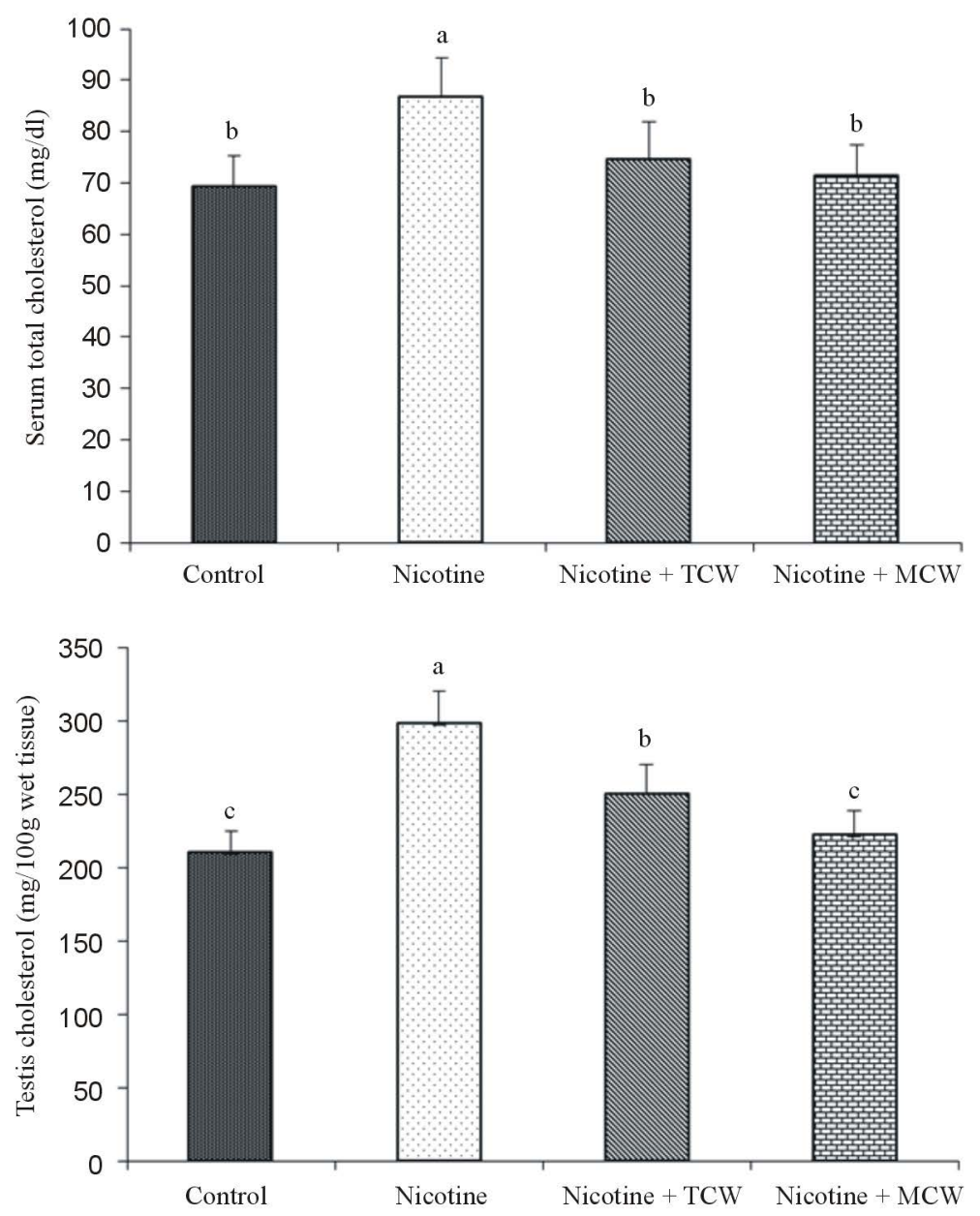

Figure 5. Effect of cosupplementation of tender and mature coconut water on concentration of serum and testis total cholesterol in nicotine treated rats. Data are expressed as mean $\pm S D(n=6)$. Columns not sharing the same superscript letter differ significantly $(\mathrm{p} \leq 0.05)$.

quality [27]. Ascorbic acid supplementation protects sperm from endogenous oxidative DNA damage that decreases abnormal sperm [28] and improves sperm quality in smokers [29]. Increase in the acid phosphatase and alkaline phosphatase reveals the degenerative changes in testicular parenchyma, followed by nicotine exposure [1]. The restoration of the activities of ACP and ALP by coconut water coadministration may be because of the significant protection of testicular cells by coconut water.

The plasma testosterone levels are considered to be a useful indicator of testicular function. Nicotine inhibits the release of androgens, LH and testosterone which are essential for the gonadal development and steroidogenesis in rats [1] [30]. In the male rats, plasma LH is responsible for maintaining the normal plasma testosterone concentration [1] [31]. The high level of testosterone in testis is essential for the normal spermatogenesis as well as for the maintenance of the structural morphology and the normal physiology of seminiferous tubule [32]. The high cholesterol content observed in the serum and tissues in nicotine treated rats also indicates the reduction in the androgen production due to lowered conversion of cholesterol to androgens which depends on the pituitary gonadotrophins. Coconut water rich in L-arginine improved the testosterone level which is in agreement with the study of Cremades [30] that reveals the dietary L-arginine can influence the testosterone level of in rodents. In addition, coconut water is proven to improve the serum cholesterol levels in rats [8]. Nitric oxide formed from L-arginine by the enzyme NOS and ascorbic acid, stimulates the secretion of follicle-stimulating hormone (FSH) and luteinizing hormone (LH) from the anterior pituitary gland and increased the level of androgens [33]. Calcium, magnesium proves to have essential role in spermatogenesis and fertility [34]. Magnesium supplementation 
increases the activities of androgenic enzymes viz. $\Delta^{5} 3 \beta$-hydroxysteroid dehydrogenase and $17 \beta$-hydroxysteroid dehydrogenase with concomitant increase in serum testosterone level [35]. Indole-3-acetic acid, plant auxin present in coconut water, is reported as main sperm protective substance [36].

From the present study, it may be suggested that coconut water ameliorates the nicotine impaired sperm and testicular functions. Finally, this study recommends further studies on pre- and post-treatment of coconut water in nicotine treated rats in order to extrapolate the results of the present study to human chronic smokers.

\section{References}

[1] Jana, K., Samanta, P.K. and De, D.K. (2010) Nicotine Diminishes Testicular Gametogenesis, Steroidogenesis, and Steroidogenic Acute Regulatory Protein Expression in Adult Albino Rats: Possible Influence on Pituitary Gonadotropins and Alteration of Testicular Antioxidant Status. Toxicological Sciences, 116, 647-659.

[2] Aydos, K., Guven, M.C., Can, B. and Ergun, A. (2001) Nicotine Toxicity to the Ultrastructure of the Testis in Rats. BJU International, 88, 622-626.

[3] Segarra, A.C. and Strand, F.L. (1989) Perinatal Administration of Nicotine Alters Subsequent Sexual Behavior and Testosterone Levels of Male Rats. Brain Research, 480, 151-159.

[4] Yamamoto, Y., Isoyama, E., Sofikitis, N. and Miyagawa, I. (1998) Effects of Smoking on Testicular Function and Fertilizing Potential in Rats. Urological Research, 26, 45-48.

[5] Lewin, A., Gonen, O., Orvieto, R. and Schenker, J.G. (1991) Effect of Smoking on Concentration, Motility and ZonaFree Hamster Test on Human Sperm. Archives of Andrology, 27, 51-54.

[6] Reddy, A., Sood, A., Rust, P.F., Busby, J.E., Varn, E., Mathur, R.S. and Mathur, S. (1995) The Effect of Nicotine on in Vitro Sperm Motion Characteristics. Journal of Assisted Reproduction and Genetics, 12, 217-223.

[7] Sinclair, S. (2000) Male Infertility: Nutritional and Environmental Considerations. Alternative Medicine Review, 5, 2838.

[8] Sandhya, V.G. and Rajamohan, T. (2006) Beneficial Effects of Coconut Water Feeding on Lipid Metabolism in Cholesterol-Fed Rats. Journal of Medicinal Food, 9, 400-407.

[9] Sandhya, V.G. and Rajamohan, T. (2008) Comparative Evaluation of the Hypolipidemic Effects of Coconut Water and Lovastatin in Rats Fed Fat-Cholesterol Enriched Diet. Food and Chemical Toxicology, 46, 3586-3592.

[10] Anurag, P. and Rajamohan, T. (2003) Beneficial Effects of Tender Coconut Water against Isoproterenol Induced Toxicity on Heart Mitochondrial Activities in Rats. Indian Journal of Biochemistry \& Biophysics, 40, 278-280.

[11] Loki, A.L. and Rajamohan, T. (2003) Hepatoprotective and Antioxidant Effect of Tender Coconut Water on Carbon Tetrachloride Induced Liver Injury in Rats. Indian Journal of Biochemistry \& Biophysics, 40, 354-357.

[12] Bhagya, D., Prema, L. and Rajamohan, T. (2012) Therapeutic Effects of Tender Coconut Water on Oxidative Stress in Fructose Fed Insulin Resistant Hypertensive Rats. Asian Pacific Journal of Tropical Medicine, 5, 270-276.

[13] Vanha-Perttula, T. and Nikkanen, V. (1973) Acid Phosphatases of the Rat Testis in Experimental Conditions. Acta Endocrinologica (Copenh), 72, 376-390.

[14] Institute of Laboratory Animal Resources, Commission on Life Sciences, National Research Council (1996) Guide for the Care and Use of Laboratory Animals. National Academy Press, Washington DC.

[15] World Health Organization (1999) Laboratory Manual for the Examination of Human Semen and Sperm Cervical Mucus Interaction. Cambridge University Press, New York.

[16] Malamy, M. and Horecker, B.L. (1966) Alkaline Phosphatase (Crystalline). In: Willis, A.W., Ed., Methods in Enzymology, Volume 9, Academic Press, Massachusetts, 639-642.

[17] Carr, J.J. and Drekter, I.J. (1956) Simplified Rapid Technic for the Extraction and Determination of Serum Cholesterol without Saponification. Clinical Chemistry, 2, 353-368.

[18] Scibona, M., Meschini, P., Capparelli, S., Pecori, C., Rossi, P. and Fabris, G.F.M. (1994) [L-Arginine and Male Infertility]. Minerva Urologica e Nefrologica, 46, 251-253.

[19] Dawson, E.B., Harris, W.A., Teter, M.C. and Powell, L.C. (1992) Effect of Ascorbic Acid Supplementation on the Sperm Quality of Smokers. Fertility and Sterility, 58, 1034-1039.

[20] Jana, K., Jana, S. and Samanta, P.K. (2006) Effects of Chronic Exposure to Sodium Arsenite on Hypothalamo-Pituitary-Testicular Activities in Adult Rats: Possible an Estrogenic Mode of Action. Reproductive Biology and Endocrinology, 4, 9.

[21] Schachter, A., Goldman, J.A. and Zukerman, Z. (1973) Treatment of Oligospermia with the Amino Acid Arginine. The Journal of Urology, 110, 311-313. 
[22] Wu, G., Bazer, F.W., Davis, T.A., Kim, S.W., Li, P., Rhoads, J.M., Satterfield, M.C., Smith, S.B., Spencer, T.E. and Yin, Y. (2009) Arginine Metabolism and Nutrition in Growth, Health and Disease. Amino Acids, 37, 153-168.

[23] Balercia, G., Moretti, S., Vignini, A., Magagnini, M., Mantero, F., Boscaro, M., Ricciardo-Lamonica, G. and Mazzanti, L. (2004) Role of Nitric Oxide Concentrations on Human Sperm Motility. Journal of Andrology, 25, 245-249.

[24] Sepaniak, S., Forges, T., Gerard, H., Foliguet, B., Bene, M.C. and Monnier-Barbarino, P. (2006) The Influence of Cigarette Smoking on Human Sperm Quality and DNA Fragmentation. Toxicology, 223, 54-60.

[25] Srivastava, S., Desai, P., Coutinho, E. and Govil, G. (2000) Protective Effect of L-Arginine against Lipid Peroxidation in Goat Epididymal Spermatozoa. Physiological Chemistry and Physics and Medical NMR, 32, 127-135.

[26] Mantena, S.K., Jagadish, Badduri, S.R., Siripurapu, K.B. and Unnikrishnan, M.K. (2003) In Vitro Evaluation of Antioxidant Properties of Cocos nucifera Linn. Water. Nahrung, 47, 126-131.

[27] Akmal, M., Qadri, J.Q., Al-Waili, N.S., Thangal, S., Haq, A. and Saloom, K.Y. (2006) Improvement in Human Semen Quality after Oral Supplementation of Vitamin C. Journal of Medicinal Food, 9, 440-442.

[28] Yousef, M.I. (2005) Protective Role of Ascorbic Acid to Enhance Reproductive Performance of Male Rabbits Treated with Stannous Chloride. Toxicology, 207, 81-89.

[29] Fraga, C.G., Motchnik, P.A., Shigenaga, M.K., Helbock, H.J., Jacob R.A. and Ames, B.N. (1991) Ascorbic acid Protects against Endogenous Oxidative DNA Damage in Human Sperm. Proceedings of the National Academy of Sciences of the United States of America, 88, 11003-11006.

[30] Seema, P., Swathy, S.S. and Indira, M. (2007) Protective Effect of Selenium on Nicotine-Induced Testicular Toxicity in Rats. Biological Trace Element Research, 120, 212-218.

[31] Sharpe, R.M., Maddocks, S., Millar, M., Kerr, J.B., Saunders, P.T. and McKinnell, C. (1992) Testosterone and Spermatogenesis. Identification of Stage-Specific, Androgen-Regulated Proteins Secreted by Adult Rat Seminiferous Tubules. Journal of Andrology, 13, 172-184.

[32] Cremades, A., Ruzafa, C., Monserrat, F., López-Contreras, A.J. and Peñafiel, R. (2004) Influence of Dietary Arginine on the Anabolic Effects of Androgens. Journal of Endocrinology, 183, 343-351.

[33] Karanth, S., Yu, W.H., Walczewska, A., Mastronardi, C.A. and McCann, S.M. (2001) Ascorbic Acid Stimulates Gonadotropin Release by Autocrine Action by Means of NO. Proceedings of the National Academy of Sciences of the United States of America, 98, 11783-11788.

[34] Wong, W.Y., Flik, G., Groenen, P.M., Swinkels, D.W., Thomas, C.M., Copius-Peereboom, J.H., Merkus, H.M. and Steegers-Theunissen, R.P. (2001) The Impact of Calcium, Magnesium, Zinc, and Copper in Blood and Seminal Plasma on Semen Parameters in Men. Reproductive Toxicology, 15, 131-136.

[35] Chandra, A.K., Sengupta, P., Goswami, H. and Sarkar, M. (2013) Effects of Dietary Magnesium on Testicular Histology, Steroidogenesis, Spermatogenesis and Oxidative Stress Markers in Adult Rats. Indian Journal of Experimental Biology, 51, 37-47.

[36] Toniolli, R., Bussiere, J., Courot, M., Magistrini, M. and Combarnous, Y. (1996) Effect of Indole-3-Acetic Acid (Plant Auxin) on the Preservation at 15 Degrees C of Boar Semen for Artificial Insemination. Reproduction Nutrition Development, 36, 503-511. 
Scientific Research Publishing (SCIRP) is one of the largest Open Access journal publishers. It is currently publishing more than 200 open access, online, peer-reviewed journals covering a wide range of academic disciplines. SCIRP serves the worldwide academic communities and contributes to the progress and application of science with its publication.

Other selected journals from SCIRP are listed as below. Submit your manuscript to us via either submit@scirp.org or Online Submission Portal.
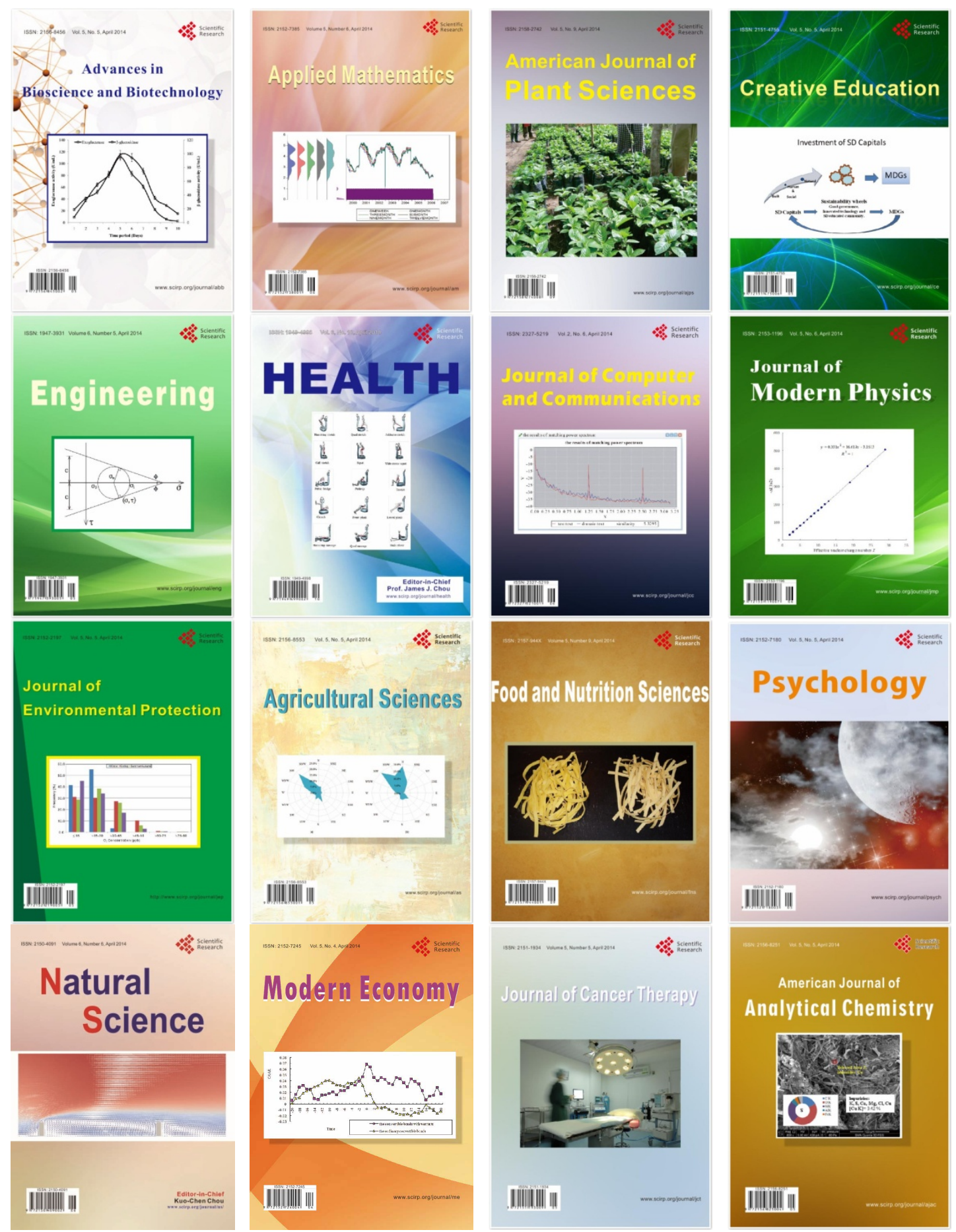